\begin{tabular}{|l|l|l||}
\hline \multicolumn{2}{|c|}{ PublisherInfo } \\
\hline \hline PublisherName & $:$ & BioMed Central \\
\hline \hline PublisherLocation & $:$ & London \\
\hline \hline PublisherImprintName & $:$ & BioMed Central \\
\hline \hline
\end{tabular}

\title{
IL-10 induces monocyte apoptosis: a clue for understanding its
} anti-inflammatory effect?

\begin{tabular}{|l|l|l||}
\hline \multicolumn{2}{|c||}{ ArticleInfo } \\
\hline \hline ArticleID & $:$ & 165 \\
\hline \hline ArticleDOI & $:$ & $10.1186 /$ ar-2000-66831 \\
\hline \hline ArticleCitationID & $:$ & 66831 \\
\hline \hline ArticleSequenceNumber & $:$ & 122 \\
\hline \hline ArticleCategory & $:$ & Paper Report \\
\hline \hline ArticleFirstPage & $:$ & 1 \\
\hline \hline ArticleLastPage & $:$ & 3 \\
\hline \hline & & RegistrationDate : 2000-8-22 \\
\hline ArticleHistory & $:$ & OnlineDate \\
\hline \hline ArticleCopyright & $:$ & Current Science Ltd2000-8-22 \\
\hline \hline ArticleGrants & $:$ & \\
\hline \hline ArticleContext & $:$ & 130753311 \\
\hline \hline
\end{tabular}




\title{
Keywords
}

\author{
Apoptosis, CD95, CD95-L, IL-10, monocyte
}

\section{Context}

IL-10 is known to have potent anti-inflammatory and immunosuppressive effects. The latter are mediated by a reduction in a wide range of different cytokines in various cell types. One of the main IL-10 effects seems to be directed towards the cytokines secreted by monocytes and macrophages (TNFa, IL-1?, IL-6, IL-8, G-CSF etc). Moreover, monocytes undergo rapid apoptosis in culture and express the death receptor CD95, suggesting that apoptosis may also participate in the IL-10 effect on monocytes. Recently, it has been shown that various Th2 cytokines (Heidenreich et al [see Additional information]), including IL-10 (Estaquier et al[see Additional information]), are able to induce apoptosis of monocytes. To understand the precise mechanisms of IL-10-induced apoptosis on human peripheral blood monocytes.

\section{Significant findings}

IL-10-induced apoptosis was dose-dependent reaching a maximum level at $100 \mathrm{U} / \mathrm{ml} \mathrm{IL-10} \mathrm{after} 72 \mathrm{~h}$ of treatment. Apoptosis was completely abrogated by an anti-IL-10 mAb, showing that the observed cell death is driven by IL-10. IL-10-induced apoptosis of monocytes was inhibited in the presence of the DEVD-CHO peptide, and IL-10 treatment of monocytes induced the cleavage of the pro-caspase- 8 into active caspase-8. These results demonstrate that these proteases are involved in IL-10-induced apoptosis. As caspase-8 is the initiator caspase in CD95-mediated apoptosis, the involvement of CD95/CD95-L interaction in IL-10-induced apoptosis was further studied. The increase of CD95 and CD95-L expression after IL-10 treatment and the inhibition of IL-10-induced apoptosis by CD95-L mAb demonstrated that IL-10-induced apoptosis is mediated by CD95/CD95-L interaction.

\section{Comments}


Interleukin (IL)-10 is a potent immunosuppressive and anti-inflammatory cytokine which is used to treat inflammatory diseases such as autoimmune bowel diseases and rheumatoid arthritis. The precise mechanism by which IL-10 exerts its effect is not entirely clear. IL-10 decreases the secretion of various cytokines in various cell types. In this paper, the authors propose a new mechanism to elucidate the IL-10 effect by providing evidence that IL-10 induces apoptosis in human monocytes. They showed that IL-10-induced apoptosis is mediated by CD95/CD95-L (ligand) interaction and involves caspase-3 and -8 activation. Knowledge of the precise mechanism of IL-10 effects (kinetics, molecular mechanisms) could be very important in improving the efficiency of IL-10 treatment of inflammatory diseases. Moreover, the implication of CD95 and CD95-L in anti-inflammatory IL-10 effects helps us to understand inflammatory autoimmune disease development in mice or humans deficient in CD95 or CD95-L.

\section{Methods}

Monocytes were purified from EDTA-treated blood of healthy volunteers. Cell death was measured by various methods, to allow the study of each step of apoptosis progression. First membrane changes were studied by measuring annexin $\mathrm{V}$ binding on phosphatidyl serine; second, DNA fragmentation was measured by using the nick end labelling (TUNEL) method, which detects breaks in the DNA strand, and by DNA separation on agarose gel, which detects internucleosomal DNA cleavage. Third, morphological features of apoptosis were studied by transmission electron microscopy. The involvement in IL-10-induced apoptosis of CD95/CD95L interaction and caspase-3 was evaluated by culturing IL-10-treated monocytes with CD95-L monoclonal antibody (mAb) and DEVD-CHO (an inhibitor of caspase- 3 activation), respectively. The conversion of pro-caspase- 8 ( $54 \mathrm{kDa}$ ) into active caspase- 8 (41-43 kDa) after IL-10 treatment was evaluated by western blot

\section{Additional information}

Heidenreich S, Schmidt M, August C, Cullen P, Rademaekers A, Pauels HG: Regulation of human monocyte apoptosis by the CD14 molecule. J Immunol 1997, 159:3178-3188 (PubMed abstract).

Estaquier J, Ameisen JC: A role for T-helper type-1 and type-2 cytokines in the regulation of human monocyte apoptosis. Blood 1994, 90:1618-1625 (PubMed abstract).

\section{References}

1. Schmidt M, Lugering N, Pauels H-G, Schulze-Osthoff K, Domschke W, Kucharzik T: IL-10 induces apoptosis in human monocytes involving the CD95 receptor/ligand pathway. Eur J Immunol. 2000, 30: 1769-1777. 